\title{
Neurophysiology uncovers secrets of TV commercials
}

\author{
Rafal Ohme • Michal Matukin · Tomasz Szczurko
}

Received: 9 December 2009 / Accepted: 19 July 2010 / Published online: 19 Octomber 2010

(C) The Author(s) 2010. This article is published with open access at Springerlink.com

\begin{abstract}
Advanced neurophysiological technologies(EEG, EMG, GSR) may serve as a bridge between what can be consciously expressed, and what is hidden in the human mind. Such application of neuroscience to advertising may finally help to better understand the interplay of attention, emotions, and arousal-constructs of great importance to advertisers. Our study tried to demonstrate how neurophysiological measures can be applied to test marketing communication and the effectiveness of creative idea execution. We aimed to show how brain waves analysis of emotional reactions to a Sony Bravia the "Balls" TV ad helps to identify a seemingly irrelevant and irrational element of this ad - i.e. the frog scene - and appreciate its instrumental, not only artistic, power. We wanted to see whether such an affective iconic priming effect occurs on a neurophysiological level and can be traced down with EEG measures and frontal asymmetry paradigm. The study confirmed most of our predictions and yielded yet another empirical example of how a small, peripheral element turned out to be a key-moment in advertising persuasion. We believe that such new measures will soon become a part of a standard research portfolio which integrates traditional, verbally-based methodologies with non-verbal brain waves based technologies.
\end{abstract}

\footnotetext{
R. Ohme $(\bowtie)$

Warsaw School of Social Sciences and Humanities,

Human Mind \& Brain Applied Research Center, Warsaw, Poland

M. Matukin

University of Opole, Human Mind \& Brain Applied Research

Center, Opole, Poland

T. Szczurko

Warsaw University of Technology, Human Mind \& Brain

Applied Research Center, Warsaw, Poland
}

Keywords Consumer neuroscience $\cdot$ EEG . Frontal asymmetry paradigm $\cdot$ Emotions . Affective iconic priming - TV advertising · Consumer research $\cdot$ Copy-testing

\section{Introduction}

The way of thinking about the human nature has recently changed quite substantially. The last two decades of the $20^{\text {th }}$ century started an alternative understanding of how people think, feel and act. "We have received our name Homo sapiens a little bit in advance", Johann Huizinga, a famous Dutch historian, once said. A number of empirical discoveries revealed that we are not as rational as it was perceived to be, our decisions are frequently based on intuition and are heavily influenced by holistic feelings rather than analytic reasoning. Since 1974, Kahneman and Tversky have been proving and showed that humans often act irrationally even if financial and health issues are at stake (in 2002 Daniel Kahneman was awarded with the Noble Prize in economics for his accomplishments in this field). If it that were not enough, since the $1980 \mathrm{~s}$ it has been systematically proven that a great amount of mental processes occur below the surface of the consciousness (Zajonc 1968, 1980, 1998; Dixon 1971, 1981; Kihlstrom 1999; Uleman and Bargh 1989; Bornstein and Pittman 1992; Greenwald and Banaji 1995; Bargh 1997; Wilson 2002; Murphy and Zajonc 1993; Dijksterhuijs 2004; Hassin et al. 2005, Jarymowicz 2001; Ohme 2003, 2007). No matter what the common sense tells us, we are driven by emotions, think in an automatic manner, and a great number of our motivations and behaviors are controlled below the conscious awareness. These are conclusions coming from methodologically rigorous psychological experiments. 
Parallel findings are uncovered by neuroscience and scholars such as Ingram (1996); Crick (1994); Adolphs et al. (1995); Dolan et al. (1996); Damasio (1994, 1999, 2003); LeDoux (1996); Gazzaniga et al. (1998); Morris et al. (1998, 1999); Panksepp and Bekkedal (1997); Öhman (1999); Dimberg et al. (2000). In neurobiology and neurophysiology it is posited that our brain is for the most part emotional, and very few structures are driven consciously and voluntarily. Similar observations can be found in the field of consumer behavior (Hazzlet and Hazzlet 1999; LaBarbera and Tucciarone 1995). Researchers like Cialdini (1984); Heath (2001); Kenning et al. (2007); Plassmann et al. (2007); Zaltman (2003); Ravaja (2004); Tellis and Ambler (2007); Ohme (2001, 2009); Ohme et al. (2009a, b; 2010) have claimed that Homo aeconomicus is wishful thinking, regardless of how difficult it is to accept this news (for example, major economic theories are still based on the assumption of rationality as the exclusive and sufficient basis for making consumer choices).

In the light of these and many other findings, it is important for the marketing industry to better understand the role of unconscious and automatic emotions in advertising communication and shopping behavior. Yet traditional marketing research is not enough for such a purpose. Conventional paper-and-pencil or verbal declarations favor pragmatism and functionality, as principles underlying consumer decisions and motives. Fortunately, a new discipline emergesconsumer neuroscience - to examine the brain and its functioning in the context of consumer choices (e.g. Kenning et al. 2007; Plassmann et al. 2007). It has been widely acknowledged that patterns of brain activity are closely related to consumers' cognition and behavior (Alwitt 1985). Thus analysis of consumers' neurophysiology may increase the understanding of psychology, i.e. how consumers process incoming information, how they use their memory and react emotionally. Moreover, as the great majority of consumer mental processes occur below the level of conscious awareness, observations of the brain reactions enable to reach the very core-i.e. consciously inaccessible - foundations of consumer decisions, emotions, motivations and preferences (Damasio 1994, 1999, 2003; Zaltman 2003).

\section{EEG application to advertising}

Nunez and Srinivasan (2006) posit that electroencephalography (EEG) is a "window of the mind", for it registers variations in brain waves produced by the cortex. Now, 80 years after its first public demonstration by Hans Berger, EEG is a very popular method used by cognitive neuroscientists, neurologists, psychophysiologists as a noninvasive and relatively inexpensive method for measuring brain activity. EEG has limited anatomical specificity, and can only gather information from the brain surface, not its deeper structures. Nevertheless, a great advantage of this method lies in a very high temporal resolution. Other techniques (e.g. functional magnetic resonance imaging) have time resolution down to a few seconds, whereas the EEG has a submillisecond one (Huettel et al. 2004). This enables researchers to precisely detect changes in the brain activity that are connected with rapidly changing stimuli. This feature is crucial for a TV advertisement's analysis.

Interest in using EEG for market research goes back to the early $1970 \mathrm{~s}$, but the first regular studies started to appear during the 1980s. In 1985 Alwitt published a study on advertisement content using EEG. She concluded that "the results of this analysis are an encouraging first look at the relationship between ongoing events and EEG-recorded brain reactions. The topic certainly warrants future research" (p. 216). Consequently, EEG has been applied to assess marketing stimuli such as media involvement (Swartz 1998), the processing of TV commercials (Rothschild et al. 1986), and the prediction of memory for components of TV commercials (Rothschild and Hyun 1990). However, the last decade has brought EEG research in consumer behavior to yet another level. The difference between old and current studies lies in the greater ease and precision with which information can be nowadays obtained and analyzed. Today's computers are much more advanced, and equipped with considerably more sophisticated statistical programs, one of which is MATLAB, a high-level technical computing language and interactive environment for data visualization, analysis, and numeric computation. Metaphorically speaking, we have moved from MS-DOS to WINDOWS applications. The latter are user friendly, handy and accessible to a wider public.

\section{Frontal Asymmetry Paradigm}

A large body of research on the relation between emotion and motivation has postulated the existence of two overarching motivational systems that organize the human behavior. One system involves behavior prompted by a possible desirable outcome, whereas the other involves behavior prompted by a possible aversive outcome (Lang et al. 1990; Carver and White 1994; Avila 2001). Davidson et al. (1979) proposed a similar model linked to research on frontal EEG asymmetry during emotional states. He proposed that the left pre-frontal cortex (PFC) is involved in a system facilitating approach behavior, whereas the right $\mathrm{PFC}$ is involved in a system facilitating withdrawal behavior from aversive stimuli. Using EEG measures to index ongoing frontal brain activity during the processing of different affects, Davidson and Fox found substantial empirical support for the model in adults and infants (for review, see: Fox 1991; Davidson 
1993; Davidson and Rickman 1999). In Davidson's model greater relative left frontal EEG activity has been routinely associated with the processing of positive affects (e.g., while viewing film clips containing pleasant scenes), whereas greater relative right frontal EEG activity with the processing of negative affects (e.g., while viewing film clips containing unpleasant scenes) (Jones and Fox 1992). In this paper we will refer to the approach related tendencies (or the left hemispheric dominance) in short as "positive reactions" and to withdrawal related tendencies (or right hemisphere dominance) as "negative reactions". Of course some negative emotional states may still evoke approach tendencies, for example anger (see: Harmon-Jones 2003), but we assume that mainstream TV commercials, in general, consist of positive stimuli (excluding social ads) and it is not very likely that their goal would be to make consumers angry.

To date, numerous independent studies have examined the relationship between emotion or emotion-related constructs and asymmetry in EEG activity over the frontal cortex. A review of these studies clearly suggests the existence of asymmetry in the frontal EEG activity, including resting levels of activity and state-related activation (Coan and Allen 2003). This asymmetry is ubiquitous and involved, both in trait predispositions to respond to emotional stimuli related to the moderating function of the prefrontal cortex, and changes in the emotional state, which can be treated as a marker of emotional intensity (Coan and Allen 2003).

The brain asymmetry either frontal or related to other brain regions is still a rather empirical and conceptual construct with obvious limitations and some competing explanations than a versatile tool to understand brain reactions to any stimuli in terms of ongoing cognitive and affective processes. Still, the quantity and quality of empirical evidence that supports Davidson's account of frontal asymmetry is compelling and we consciously opted for a theory-driven research than purely data-driven research (to be followed by model-oriented and theoretical work). Therefore, results of our study should be viewed in the context of this choice and its interpretative consequences, especially.

\section{Research problem}

Findings from the previous study

In one of our previous studies (Ohme et al. 2010) we compared three consecutive creative executions of the worldfamous Sony Bravia flat TV ads ("Balls", "Paints", and "Play-Doh"). It turned out that the left hemispheric dominance - an indicator of positive reactions - was present only in response to one of the tested ads: "Balls". This ad consists of two parts - the first emotional one focuses on showing vital, youthful and vibrant colors by presenting a spectacu- lar, specially organized event. The opening scene shows a distant frame of an urban landscape of San Francisco and a moment later, impressive scenes of jumping balls. This effect is enriched with a beautiful and nostalgic song in the background. In the end of this part, all the colors are integrated, illustrating the explosion of color. The second informational part presents Sony Bravia benefits, the product itself, and the logo. Between the two parts, there is a short scene of a frog jumping out of a rain pipe (see: Appendix for more details on the ad). The "Balls" ad successfully conveyed the message: the colors offered by Sony Bravia TVs are unique, they are "like no other" the slogan says. The ad reportedly increased sales, the film itself got much attention among consumers all around the world, and its creators won prestigious awards, including the Golden Lion in Cannes in June 2006.

We found out that the respondents reacted positively to both parts of the ad-the emotional and the informational ones (op.cit.). We also noticed that the scene that evoked the strongest left hemispheric dominance within the emotional part was the scene where the frog jumps out of the rain pipe. We were quite surprised to learn this, because in qualitative in-depth interviews, this very short (lasting less than 2 seconds) scene is frequently not even noticed by the viewers, and once enquired about it is considered as "funny but irrelevant" (Ohme et al. 2009b). As the informational part has generated a high level of positive reactions the question arises whether the informational part and the frog scene are anyhow related or rather independent?

Is the frog an iconic affective prime?

We decided to conduct a new research to better understand the frog phenomenon. We have identified that a seemingly unimportant and irrational element - the frog scene-elicited strong left hemispheric dominance reactions. Furthermore, this very element briefly precedes the informational part which turned out to produce significant positive reactions as well. We wanted to find out if the same occurred, had the frog scene been discarded from the ad. If the left hemispheric dominance was maintained, even during the absence of the frog scene, we would consider it as positive but irrelevant to the main message of the ad. However, if the left hemispheric dominance was maintained only when "the frog scene" is present, we would consider it as positive and instrumental to the main message of the ad. We would consider it an affective iconic prime.

A priming phenomenon increases sensitivity to a certain stimuli due to a prior experience. Research has shown that priming can impact various cognitive operations including memory and decision-making processes (Jacoby 1983). In their seminal 1993 study Murphy and Zajonc provided an empirical evidence that if a presentation of iconic affective 
primes (pictures of facial expressions) precedes exposure of a neutral target stimulus (e.g. Chinese ideographs), the affective reactions from the prime transfer to the target and elicit shifts in conscious judgments of the target in comparison to the condition without priming (see also Murphy et al. 1995). Zajonc's affective primacy hypothesis (Zajonc 1980, 1998; Murphy and Zajonc 1993) holds that such affective reactions can be elicited even without subject's conscious awareness at all (see also: Kunst-Wilson and Zajonc 1980; Seamon et al. 1984).

In this paper we have decided to explore the concept of priming in advertising. We wanted to see if it is the iconic affective priming phenomenon that occurs in the Sony Bravia "Balls" ad, with the frog scene being a prime, and the informational scene being a target. We wanted to see whether such priming effect occurs on a neurophysiological level and can be traced down with brain waves based measures and frontal asymmetry paradigm.

\section{Method}

\section{Description of the stimuli}

We tested two versions of the Sony Bravia, the "Balls" ad. The first one will be described in this paper as the frog version, and the second one-in which we removed the sequence with the frog jumping out of the rain pipe - as the without frog version. To estimate a possible duration time of the priming effect (if it exists at all), we decided to divide the informational part into three shorter fragments. These were consistently identified by five independent advertising experts as: (1) benefit scene (a word "color" appeared on the screen), (2) product scene (Sony Bravia TV exposure) and (3) brand scene (Sony logo exposure).

\section{Participants and procedure}

The research was conducted on 40 healthy, right-handed respondents $(50 \%$ females, $50 \%$ males), aged $25-50$ $(\mathrm{m}=34.2 \mathrm{SD}=5.7)$, with an income average plus, planning to buy a flat screen TV within three months from the research. The recruitment took place around shopping areas. Participants were informed that they would watch a series of commercials while their neurophysiologic responses would be registered. They were paid for participation. Upon arrival everybody was informed that they would watch several TV commercials within the next 20 minutes. Participants were left alone, their behavior was constantly monitored by a camera. They were asked to look carefully at the compu- ter screen, additionally, a countdown screen was presented before the presentation of each ad.

There were no specific tasks given during the presentation. The ads were shown in one block consisting of 9 spots. A within subjects design was used. Each participant was presented with the both versions of the Sony ad. First they watched the without frog version, and after 30 minutes - the frog version. It is consistent with a within subject designfirst, there is a stimulus, then a "modification" is implemented and then, the second measurement is taken (Field 2005; Ferguson and Takane 1989). This kind of procedure has several advantages. Most importantly it reduces the unsystematic variability in a sample and provides greater power to detect subtle effects (and was therefore used by Murphy and Zajonc in their studies).

\section{Apparatus}

The presentation was shown on a 19-inch computer screen. Presentation $^{\mathrm{TM}}$ software was used for stimulus exposition and to synchronize the EEG to the video footage. During the presentation the cortical responses of the respondents were registered. A 32 channel Brain Vision amplifier was used. The electrodes were located in accordance with the 10-20 International Electrode Placement System (Cacioppo et al. 2000). The recordings were obtained from the prefrontal and frontal regions of the cortex (Fp1, Fp2, F3, F4, F7, F8). The power of alpha band $(8-12 \mathrm{~Hz})$ in each of the frontal electrodes was calculated using Fast Fourier Transformation with coherent power gain correction applied (Hanning window). Then the alpha power was corrected using the reference power calculated as a mean power in the frequencies of 3-70 Hz in each electrode. The alpha power in the ipsilateral electrodes was averaged and compared to the power of contra lateral electrodes. Left hemispheric dominance was indicated by a relatively greater left hemispheric activation in the frontal and prefrontal regions (measured in the alpha band), and right hemispheric dominance was indicated by a greater right hemispheric activation. The activity of left and right hemisphere was then subtracted to obtain the asymmetry index which indicates left or right hemisphere's dominance.

Questions and hypotheses

Our main question was what would have happened if the Sony Bravia the "Balls" ad was deprived of the frog scene, i.e. the positive affective stimulus? How would it influence the informational part of the ad? Is it possible, that such a subtle (often unnoticed and unremembered on the conscious level) stimulation could produce a positive effect, that is 
being transferred to the next scenes? How will the prefrontal reaction profile change if we remove the frog scene?

In frontal asymmetry paradigm studies, a priming affect can be assessed on two levels: a direct and relative or indirect and absolute. The former comes from a comparison of reactions to primed versus not primed stimulation. The latter comes from a comparison of reactions to the primed stimulation and the baseline (resting state) activation. Consequently, we have formulated the following six hypothesis:

H1: Left hemispheric dominance during the informational part will be greater when this part is primed with a positive affective stimulus (the frog scene), comparing to left hemispheric dominance in the no priming condition.

H2: The reaction to the informational part with positive affective priming will be positive i.e. there will be a relatively stronger left prefrontal activation compared to the baseline activation.

H3: The reaction to the informational part without positive affective priming will be neutral, i.e. there will be a relative balance between left and right prefrontal activation compared to the baseline activation.

According to the fragmentation of the informational part, we have formulated three additional hypotheses:

H4: Left hemispheric dominance during each of the three following fragments of the informational part (i.e. benefit, product, and brand scenes) will be greater when this part is primed with a positive affective stimulus, comparing to left hemispheric dominance in the no priming condition.

H5: The reaction to each of the three following fragments of the informational part with a positive affective priming will be positive, i.e. there will be a relatively stronger left prefrontal activation compared to the baseline activation.

H6: The reaction to each of the three following fragments of the informational part without positive affective priming will be neutral, i.e. there will be a relative balance between the left and right prefrontal activation compared to the baseline activation.

\section{Results}

The data has been tested using within-group $t$ test. Type one errors (alpha) have been adjusted applying Bonferroni correction in order to account for multiple tests conducted. All assumptions for the test were met.

Testing the main hypotheses

$\mathrm{H} 1$ is declined. The dependent variable in the test was the asymmetry index averaged across the informational parts of primed and not primed versions.

There are no statistically significant differences between the reaction to the informational part between the primed and not primed versions $(\mathrm{m}=0.49$ versus $\mathrm{m}=0.33$, $\mathrm{t}(37)=-0.801, \mathrm{p}>0.05, \mathrm{SD}=1.41)$

$\mathrm{H} 2$ is confirmed. The dependent variable in the test was the asymmetry index averaged across the informational parts of primed and not primed versions.

In the version with affective positive priming the informational part has a relatively stronger left prefrontal activation compared to the baseline activation $(\mathrm{m}=0.49, \mathrm{t}(37)=2.800$, $\mathrm{p}<0.008, \mathrm{SD}=1.24$ ) (Fig. 1)

H3 is confirmed. The dependent variable in the test was the asymmetry index averaged across the informational parts of primed and not primed versions.

In the version without positive affective priming the informational part is in a relative balance between the left and right prefrontal activation compared to the baseline activation. (Fig. 1)

Testing the additional hypotheses

$\mathrm{H} 4$ is declined. The dependent variable in the test was the asymmetry index averaged for each of the informational parts' fragments of primed and not primed versions. The comparisons between the conditions indicated no statistically significant differences between the left hemispheric dominance in response to the scenes presenting benefit, product and brand.

$\mathrm{H} 5$ is partly confirmed. The dependent variable in the test was the asymmetry index averaged for each of the informational parts' fragments of primed and not primed versions.
Fig. 1 Comparison of mean reactions to the informational part of the primed and not primed version of the ad; [*] indicates $\mathrm{p}<0.05$ indicates difference from baseline

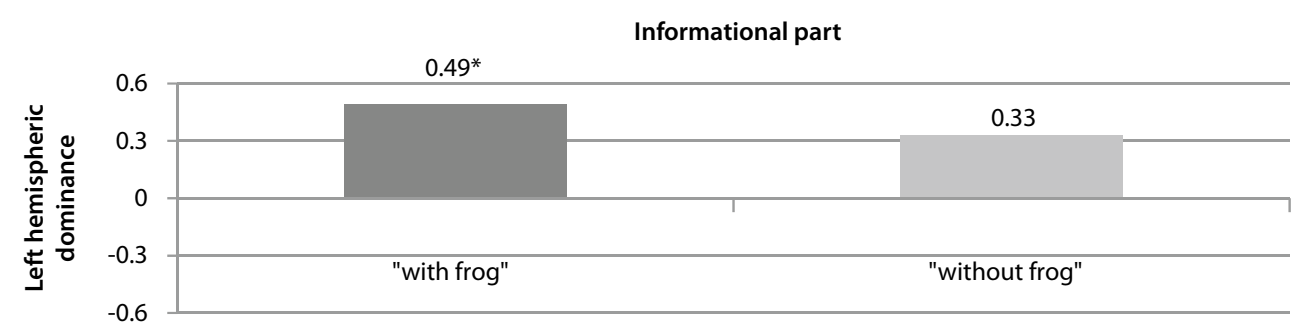


Fig. 2 Comparison of mean reactions to each of the three segments of the informational part of primed "with frog" and unprimed "without frog" versions of the ad [*] indicates $\mathrm{p}<0.05$ difference from baseline

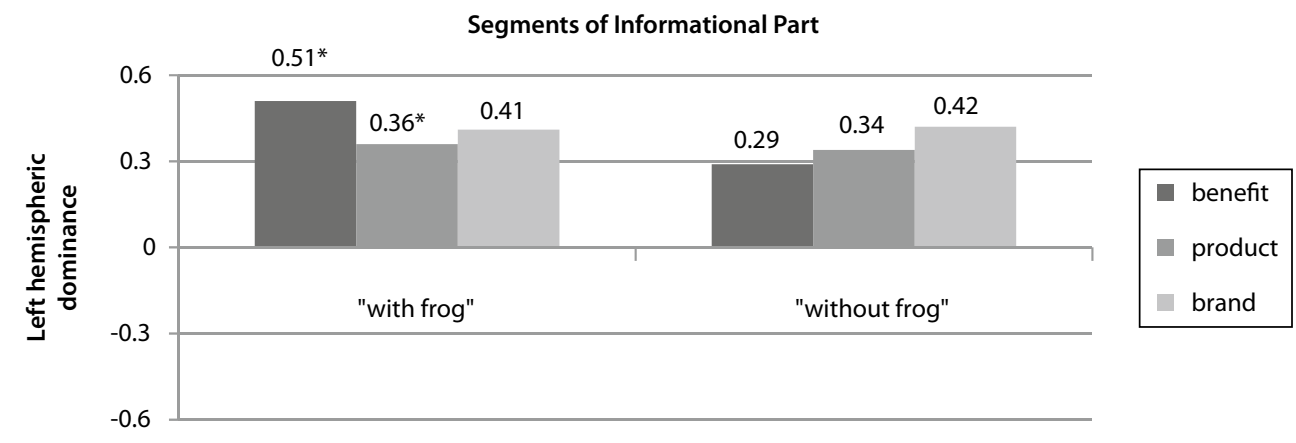

First two fragments following the frog scene: benefit exposure and product exposure scenes generated a statistically significant left hemispheric dominance: benefit scene: $\mathrm{m}=0.51, \mathrm{t}(37)=2.305 ; \mathrm{p}=0.03 \mathrm{SD}=1.38$; product scene $\mathrm{m}=0.36, \mathrm{t}(37)=1.99 ; \mathrm{p}=0.05, \mathrm{SD}=1.11$. The third fragment-brand scene did not reach level of statistical significance $(\mathrm{m}=0.41, \mathrm{t}(37)=1.356, \mathrm{p}>0.05, \mathrm{SD}=1.85$ (Fig. 2).

H6 is confirmed. The dependent variable in the test was the asymmetry index averaged for each of the informational parts' fragments of primed and not primed versions. In the version without priming there is a relative balance between the left and right prefrontal activation compared to the baseline activation. It occurs for the benefit scene $(\mathrm{m}=0.29, \mathrm{t}(38)=1.236, \mathrm{p}>0.05, \mathrm{SD}=1.48)$, for the product scene $(\mathrm{m}=0.34, \mathrm{t}(38)=1.75 ; \mathrm{p}=0.09, \mathrm{SD}=1.85)$, and for the brand scene $(\mathrm{m}=0.42, \mathrm{t}(38)=1.140, \mathrm{p}>0.05, \mathrm{SD}=2.28)$ (Fig. 2). Note that in both versions the brand scene has generated high positive results, however the variance was too high and eventually the result has not reached a level of significance.

\section{Discussion}

The main goal of our study was to reveal how one scene may efficiently prime other scenes on a neurophysiological level. We found that the primed informational part evokes strong positive reactions, whereas reactions to it when no priming is available are neutral. After dividing the informational part into three segments we found positive reactions to the product benefits exposure but again only in the primed version. Reactions toward the remaining two segments (product and brand exposures) did not differ significantly between the primed and not primed versions. It may indicate that the duration of the priming effect is limited. However, at this early stage this finding has to be considered an observation rather than an established fact.

The results support Zajonc and Murphy's (1993) findings that positive iconic priming results in the increase in positivity toward the primed target. Moreover, this study conceptually extends their notion of the diffusion of unconscious affect (i.e. a transfer of positivity or negativity from an affective prime onto neutral or ambiguous target). We have discovered that such diffusion is possible for optimal (consciously accessible) primes, whereas Zajonc and Murphy posited that it is restricted to suboptimal (consciously inaccessible) activation only. Our results do not contradict Murphy and Zajonc's findings as we analyzed neurophysiological reactions whereas they had focused on conscious responses. To better address this issue in the next research, we will not only use EEG measures but also introduce conscious evaluations, both on interval and continuous scales (see: Ohme et al. 2009b).

The research reveals that a prime stimulus - the frog scene - turned out to be instrumental in spite of the fact how irrelevant to the flat TV product category it seemed to be. It is hard to imagine indeed - particularly prior to learning the outcomes of this research - how to associate, on a rational level, a frog jumping out of a gutter with a high technology product such as a plasma TV. Moreover, the duration of the frog scene was approximately $5 \%$ of the whole ad, and it still managed to produce a significant impact. It is yet another example of how a small, peripheral element turned out to be a key-moment in advertising persuasion. In one of our studies (Ohme et al. 2009a) we showed that a subtle gesture, verbally neglected by respondents on the conscious level, altered not only their neurophysiological (EEG, EMG, GSR) reactions, but also made a positive impact on the perception of a pharmaceutical product (reflected by the increase in the product benefits conscious evaluations) as well as on their purchase oriented behaviors (reflected by the increase in the number of shelf-test choices of the product). In the future, as we come into possession of more of such cases we would be able to theoretically advance the concept of a three-dimensional advertising in which such subtle, peripheral, unconscious, often utterly irrelevant cues (rationally speaking of course) turn out to be instrumental in driving purchase oriented behavior of consumers (Ohme 2009).

Interestingly, it is said that the frog scene-the crucial moment of the ad as revealed by the brain-waves analysis - was not strategically pre-planned by the advertiser nor by the agency. A frog just happened to be there while shooting the commercial, and only thanks to the creators' gut 
feelings was kept in the final cut. It is quite an example of how hard work and talent should be married to intuition and luck to produce a good ad. Unless the brain-waves based test is at hand, of course. It is now self-evident that neurophysiological research may offer much greater control over the creative advertising process, and eventually may help utilize both expected and accidental findings. To illustrate this, considering the Sony Bravia 2005 campaign one may recommend to use "a frog insight" as an inspiration to retail communication (e.g. at store displays, points of purchase, leaflets, brochures, etc.) and to have frog-like visuals replace immortal Hawaiian sunsets.

\section{Conclusions: implications to the market research industry}

Our study tried to demonstrate how neurophysiological measures can be applied to test marketing communication and the effectiveness of a creative idea execution. Conventional methods provide conscious and holistic evaluations of ad effectiveness, whereas neurophysiological methods enable unconscious and analytic, second by second evaluations. That is why EEG, EMG, GSR analysis should be used as sources of complimentary information to estimate a continuous impact of key elements (branding exposure, product scenes, demo animations or voice over), as well as to optimize formal artistic solutions (sound tracks, sound effects, various creative ideas, etc) in ads copy-testing. Thanks to such continuous measurements we may discover causal relationships within advertising communication to which methods based on traditional verbal data collection are frequently blind.. Sooner than later such new measures will become a part of a standard research portfolio which integrates traditional, verbally-based methodologies with new, non-verbal technologies.

We strongly support an argument of the significance of emotions in advertising. Not only with respect to making ads a more likeable and pleasant but most importantly to making them a more persuasive product-wise and brandwise. The Sony Bravia study shows that a seemingly irrational, emotional stimulus has an ability to create positive associations between the commercial and the product benefit. Although this notion is not quite new to many marketing experts (who can intuitively sense the role of emotional peripheral stimuli) they frequently face difficulties to prove this phenomenon exists. It is because they use verballybased traditional methods. At the same time, arguments provided by a brain-waves based, non-verbal method are clear, univocal and practical. The brain wave method we presented here equips researchers with an additional instrument to verify and upgrade existing methods and to explore the area of unconsciousness and emotions.

Due to a constant technological advancement of neurophysiological hardware and software two out of three barriers of entry have been already overcome. Firstly, the price of the research has been rapidly reduced and reached the level similar to traditional methods. Secondly, processes of data collection and data analyses become less complex and thus are accessible to a wider audience of researchers. There is one more barrier left-a natural threat against novelty and status quo changes. However, thanks to the exponential growth of consumer neuroscience publications (of which this Special Edition is a good example), meetings (for instance NeuroConnections Global Conference), international undertakings (Advertising Research Foundation and its Cross-Cultural Brain Study) and other scientific and popular education this last barrier should disappear as well. 


\section{Appendix}

Description of the Sony Bravia the "Balls" 2005 TV ad

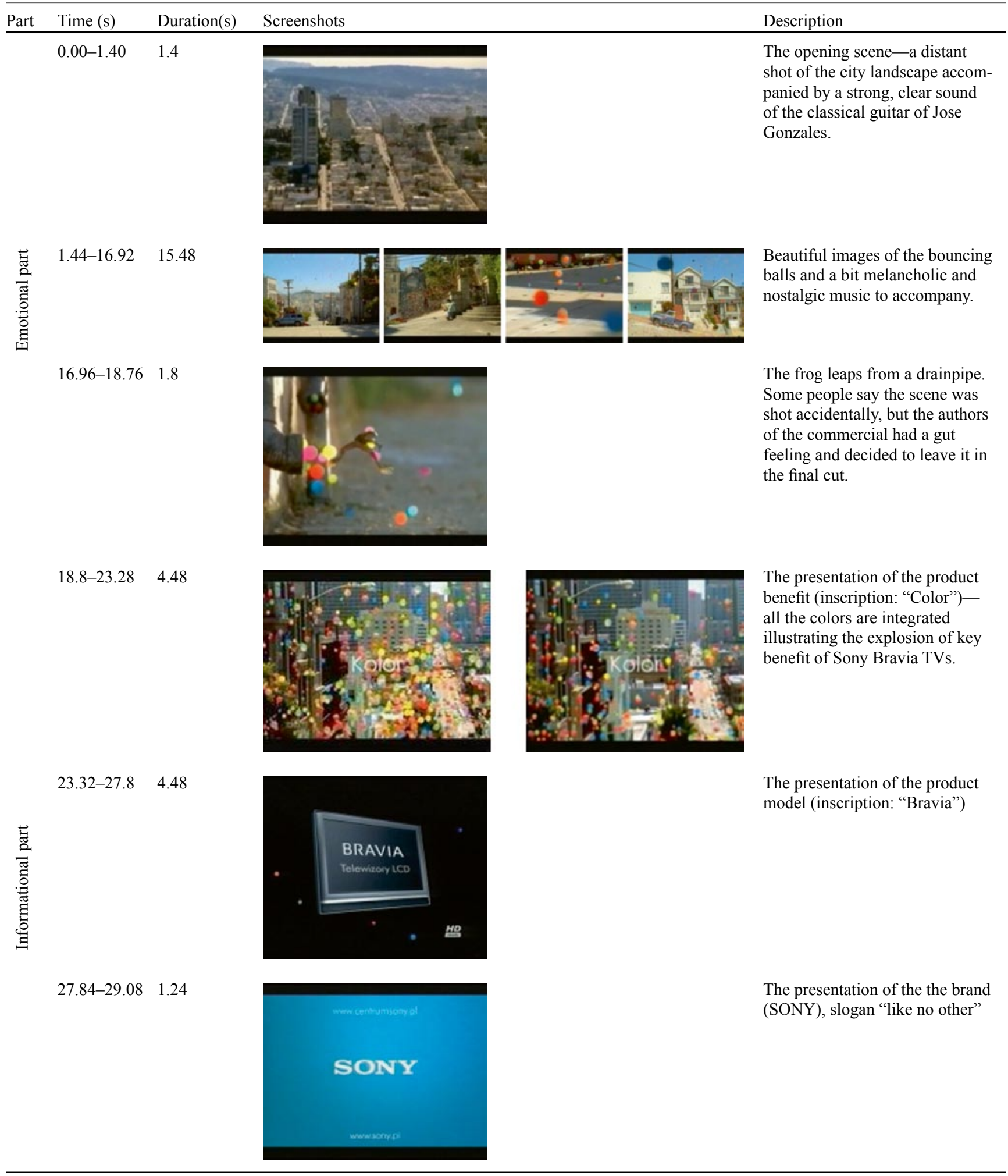


Open Access This article is distributed under the terms of the Creative Commons Attribution Noncommercial License which permits any noncommercial use, distribution, and reproduction in any medium, provided the original author(s) and source are credited.

\section{References}

Adolphs R, Tranem D, Damasio H, Damasio AR (1995) Fear and the human amygdala. J Neurosci 15(9):5879-5891

Alwitt LF (1985) EEG activity reflects the content of commercials. In: Alwitt LF, Mitchell AA (Eds) Psychological processes and advertising effects: theory, research, and applications. Lawrence Erlbaum, Hillsdale, pp 209-219

Avila C (2001) Distinguishing BIS-mediated and BAS-mediated disinhibition mechanisms: a comparison of disinhibition models of Gray (1981, 1987) and of Patterson and Newman (1993). J Pers Soc Psychol 80:311-324

Bargh JA (1997) The automaticity of everyday life. In: Wyer RS Jr (Ed) The automaticity of everyday life: advances in social cognition, Vol 10. Erlbaum, Mahwah, pp 1-61

Bornstein RF, Pittman TS (1992) Perception without awareness. The Guilford Press, New York

Cacioppo JT, Tassinary LG, Berntson GC (2000) Handbook of Psychophysiology, 2nd Ed. Cambridge University Press, NY

Carver CS, White TL (1994) Behavioral inhibition, behavioral activation, and affective responses to impending reward and punishment: the BIS/BAS scales. J Pers Soc Psychol 67(2):319-333

Cialdini RB (1984) Influence. How and why people agree to things. William Morrow \& Co. Inc., New York

Coan JA, Allen JJB (2003) Frontal EEG asymmetry and the behavioral activation and inhibition systems. Psychophysiology 40:106-114

Crick F (1994) The astonishing hypothesis: the scientific search for the soul. Touchstone, New York

Damasio AR (1994) Descarte's error. Emotion, reason, and the human brain. Putnam's Sons, NY

Damasio AR (1999) The feeling of what happens: body and emotion in the making of consciousness. Harcourt Brace, New York

Damasio AR (2003) Looking for spinoza: joy, sorrow and the feeling brain. William Heinemann, London

Davidson RJ (1993) The neuropsychology of emotion and affective style. In: Lewis M, Haviland JM (Eds) Handbook of emotion. Guilford Press, New York, pp 143-154

Davidson RJ, Rickman M (1999) Behavioral inhibition and the emotional circuitry of the brain: Stability and plasticity during the early childhood years. In: Schmidt LA, Schulkin J (Eds) Extreme fear, shyness, and social phobia: origins, biological mechanisms, and clinical outcomes. Oxford University Press, New York, pp 67-87

Davidson RJ, Schwartz GE, Saron C, Bennett J, Goleman DJ (1979) Frontal versus parietal EEG asymmetry during positive and negative affect. Psychophysiology 16:202-203

Dijksterhuijs A (2004) Think Different: The merits of unconscious thought in preference development and decision making. J Pers Soc Psychol 87(5):586-598

Dimberg U, Thunberg M, Elmehed K (2000) Unconscious facial reactions to emotional facial expressions. Psychol Sci 11(1):86-89

Dixon NF (1971) Subliminal perception: the nature of controversy. McGraw-Hill, London

Dixon NF (1981) Preconscious processing. Wiley, New York

Dolan RJ, Fletcher P, Morris J, Kapur N, Deakin JF, Frith CD (1996) Neural activation during covert processing of positive emotional facial expressions. NeuroImage 12(4):194-200
Ferguson G, Takane Y (1989) Statistical analysis in psychology and education, 6th edition, McGraw-Hill, New York (1959)

Field AP (2005) Discovering statistics using SPSS, 2nd edition. Sage, London

Fox NA (1991) If it's not left, it's right: electroencephalograph asymmetry and the development of emotion. Am Psychol 46:863-872

Gazzaniga MS, Ivry RB, Mangun GR (1998) Cognitive neurosciencethe biology of the mind. W.W. Norton \& Co., New York

Greenwald AG, Banaji MR (1995) Implicit social cognition: attitudes, self-esteem, and stereotypes. Psychol Rev 102:4-27

Harmon-Jones E (2003) Anger and behavioural approach system. Pers Individ Dif 35:995-1005

Hassin RR, Uleman JS, Bargh JA (red.) (2005) The new unconscious. Oxford University Press, New York

Hazzlet RL, Hazzlet SY (1999) Emotional response to television commercials: facial EMG vs. Self report. J Advert Res 39:7-23

Heath R (2001) The hidden power of advertising: how low involvement processing influences the way we choose brands. Admap Publications, Henley-on-Thames

Huettel SA, Song AW, McCarthy G (2004) Functional magnetic resonance imaging. Sinauer Associates, MA

Ingram J (1996) The burning house: unlocking the mysteries of the brain. Penguin Books Ltd., Toronto

Jacoby LL (1983) Perceptual enhancement: persistent effects of an experience. J Exp Psychol Learn Mem Cogn 9:21-38

Jarymowicz M (Ed) (2001) Pomiędzy afektem i intelektem: poszukiwania empiryczne. (Between affect and intelect: empirical explorations) Wydawnictwo IP PAN, Warszawa

Jones NA, Fox NA (1992) Electroencephalogram asymmetry during emotionally evocative films and its relation to positive and negative affectivity. Brain Cogn 20:280-299

Kenning P, Plassmann H, Ahlert D (2007) Applications of functional magnetic resonance imaging for market research. Qual Mark Res 10(2):135-152

Kihlstrom JF (1999) Conscious versus unconscious cognition. In: Sternberg RJ (Ed) The nature of cognition. MIT Press, Cambridge, pp 173-203

Kunst-Wilson WR, Zajonc RB (1980) Affective discrimination of stimuli that cannot be recognized. Science 207:557-558

LaBarbera PA, Tucciarone JD (1995) GSR reconsidered: a behaviorbased approach to evaluating and improving the sales potency of advertising. J Advert Res 35:33-53

Lang PJ, Bradley MM, Cuthbert BN (1990) Emotion, attention, and the startle reflex. Psychophysiol Rev 97:377-398

Le Doux J (1996) The emotional brain. Simon \& Schuster, New York

Morris JS, Öhman A, Dolan RJ (1998) Conscious and unconscious emotional learning in the amygdala. Nature 393:467-470

Morris JS, Öhman A, Dolan RJ (1999) A subcortical pathway to the right amygdala mediating "unseen" fear. Proc Natl Acad Sci 96:1680-1685

Murphy ST, Zajonc RB (1993) Affect, cognition, and awareness: affective priming with suboptimal and optimal stimulus. J Pers Soc Psychol 64:723-739

Murphy ST, Monahan JL, Zajonc RB (1995) Additivity of nonconscious affect: combined effects of priming and exposure. J Pers Soc Psychol 69(4):589-602

Nunez PL, Srinivasan R (2006). A theoretical basis for standing and traveling brain waves measured with human EEG with implications for an integrated consciousness. Clin Neurophysiol $11: 2424-2435$

Ohme RK (2001) The implicit conditioning of consumer attitudes: Logo substitution effect. Pol Psychol Bull 32(1):71-78

Ohme R (2003) Podprogowe Informacje Mimiczne (Subliminal Facial Cues). IP PAN \& SWPS, Warsaw

Ohme R (2007) Nieuswiadomiony Afekt (Unconscious Affect). GWP, Sopot 
Ohme R (2009) The unconscious as the third dimension in advertising. American Advertising Newsletter 5(4):1-5

Ohme RK, Reykowska D, Wiener D, Choromańska A (2009a) Analysis of neurophysiological reactions to advertising stimuli via EEG and GSR measures. J Neurosci Psychol Econ 2(1):21-31

Ohme RK, Jagielska M, Wnuk A (2009b) Integrating qualitative methods with biometrics Exploring consumers' minds in response to TV commercials. Paper presented at the ESOMAR Annual Conference: Qualitative 2009 The Evolving Human. Marrakech, 15-17 November 2009

Ohme RK, Reykowska D, Wiener D, Choromańska A (2010) Application of frontal EEG asymmetry to advertising research: Sony Bravia case. J Econ Psychol—Special Issue: Decisions Neurosci (In press)

Öhman A (1999) Distinguishing unconscious from conscious emotional processes: methodological considerations and theoretical implications. In: Dalgeish T, Power M (Eds) Handbook of cognition and emotion. Wiley, New York, pp 321-352

Panksepp J, Bekkedal MYV (1997) The affective cerebral consequences of music: happy vs. sad effects on the EEG and clinical implications. Int J Arts Med 5:18-27

Plassmann H, Ambler T, Braeutigam S, Kenning P (2007) What can advertisers learn from neuroscience? Int J Advert 26:151-175

Ravaja N (2004) Contributions of Psychophysiology to Media Research: Review and Recommendations. Media Psychology 6(2):193-235

Rothschild M, Thorson E, Reeves B, Hirsch J, Goldstein R (1986) EEG activity and the processing of television commercials. Communic Res 13(2):182-220
Rothschild M, Hyun YJ (1990) Predicting memory for components of TV commercials from EEG. J Consum Res 16(4):472-478

Seamon JG, Marsh RL, Brody N (1984) Critical importance of exposure duration for affective discrimination of stimuli that are not recognized. J Exp Psychol Learn Mem Cogn 10:465-469

Swartz BE (1998) Timeline of the history of EEG and associated field. Electroencephalogr Clin Neurophysiol 106:173-176

Tellis GJ, Ambler T (Ed) (2007) The SAGE handbook of advertising. Sage, CA

Uleman JS, Bargh JA (1989) Unintended thought. Guilford Press, New York

Wegner DM (2002) The illusion of conscious will. MIT Press, Cambridge

Wilson TD (2002) Strangers to Ourselves. Discovering the adaptive unconscious. The Belknap Press of Harvard University Press, Cambridge

Zajonc RB (1968) Attitudinal effects of mere exposure. J Pers Soc Psychol 9:1-27

Zajonc RB (1980) Feeling and thinking: preferences need no inferences. Am Psychol 35:151-175

Zajonc RB (1998) Emotions. In: Gilbert DT, Fiske ST, Lindzey G (Eds) The handbook of social psychology, vol 1. McGraw-Hill, New York, pp 591-632

Zaltman G (2003) How customer think. Essential insight into the mind of the market. Harvard Business School Press, Harvard 